\title{
Innovative Reflections on Music Students' Social Practice and Professional Education Integration Activities in Universities
}

\author{
Xiaorui Guo \\ Northeast Normal University \\ Changchun, China
}

\begin{abstract}
The paper takes the perspective of college counselors from the frontline and the professional support of students majoring in music as the background, while the actual conditions of contemporary Chinese college students are the premise, emphasizing the necessity of integrating professional education and social practice closely in the aspect of personnel training, which not only help to train the professional thinking and professional skills of students in practical applications, but also facilitate to enhance the overall quality of students from the perspective of practical education. This paper explores the integration of social practice and professional education for music majors in universities, and proposes creative work ideas and practical application cases.
\end{abstract}

Keywords-music professional education; practice education; application cases

\section{INTRODUCTION}

"The theory is gray, but the tree of life is evergreen." Students of music majors carry out activities integrating social practice and professional education in universities. In the creative learning atmosphere and environment where students think it different from classroom teaching modes, the music majors use practices to test theories and give students subjective real acceptance and feedback of classroom teaching results. They examine the differences between individual ability and the development needs of social talents, and flexibly exert the dual educative effects of professional education and quality education.

At the same time, while the activity design is based on cultivating talents adapted to social development, it should also adhere to the "people-oriented" education ethic, respect students' individuality to explore development differences, and pay attention to responding to students' own needs, so as to provide students with more open ideas, more comprehensive and diversified development platform.

\section{ANALYSIS ON THE CURRENT SitUATION OF PROFESSIONAL PRACTICE OF MUSIC MAJORS}

In recent years, while domestic universities have been vigorously deepening the practice of educating people, they are actually training people who are more in line with "social needs."In addition to emphasizing "professional competence" during graduate recruitment of employing unit, the mainstream trend is actually the "quality and ability". The primary problem lies in the fact that many graduates are not able to fully adapt to the needs of the society after getting out from the campus according to employers, which is neatly illustrated by the lack of capacity, innovation and social adaptability.

\section{A. High Priority but Low Popularity of Professional Education Practice Courses}

In terms of the training of some domestic universities, professional education and quality education have always been regarded as two parallel disciplines, but the integration in the curriculum is mainly reflected in professional probation and practice courses. According to the author's understanding, a small number of normal colleges and universities have now increased the number of educational apprenticeship courses in their first year of schooling. This shows that for today's college students, practical education is not only an opportunity for higher grade students to train themselves and verify their professionalism, but also to inspire junior students to go into deeper level of awareness and exploration aspiration for their professions, that is to say, practical education should be popularized in all stages of university education. Therefore, only the deeper and more flexible use of professional education and quality education, which are independent and complementary to each other, will combine the rational knowledge gained by the students from the first classroom with the perceptual knowledge gained through social practice, thereby deepening the mastery of professional knowledge. Only so, ${ }^{1}$ the fundamental goal of achieving talent cultivation can be achieved.

\section{B. Formalized Professional Practice with Low Practicability}

Music students do not seem to lack social practice activities, such as a wide variety of competitions and rich experience in performances, but even for the music majors of 29 independent art colleges in China, their mainstream employment direction is not professional performers or singers, not to mention the employment trends of music majors in other

Wang Bingnan. Research on the Social Practice Mode of College Students Combined with Specialized Education [G]. Journal of North University of China (Social Science Edition), 2011 
colleges and universities and music students in comprehensive institutions. Therefore, although the stage experience is part of the composition of the qualities of the music major students, the professional practice forms in the society are not the same as the classroom practice under the teaching system. So, more diverse perspectives are needed for training, such as strengthening the training for the use of students' professional knowledge and comprehensive skills in campus practice activities as well as a wider range of practical forms for practical purposes.

\section{ANALYSIS OF THE CURRENT SITUATION OF SOCIAL PRACTICE OF MUSIC MAJORS}

Most universities in China regard social practice activities in universities as one of the main positions of quality education for college students. As a first-line college counselor, the author deeply understands that this part of the practice is often better performed in schools and departments of science and technology and art. Meanwhile, the author also feels the difficulty and dilemma of the music students to carry out campus practice activities.

In practice, undergraduates are the main body in practical activities, transforming the objective world through social practice, and transforming their own subjective world through social practice. ${ }^{2}$ Although there are many kinds of practical activities on campus at the moment, the mainstream trends of various professions are still debate competitions, choir competitions, campus singer competitions, host contests, thematic reportage art shows, fancy dress parties, etc. For such students in science and technology and art department, all kinds of activities are integrated into the literary elements and use the active campus life to be decorated, which mobilizes the enthusiasm of them. Although professional disparities make it difficult to carry out activities, due to the students' imperative awareness of subjective participation, they are more likely to actively think about and solve problems and fully exercise their organizational and practical skills, which leads to better effects. For music majors, choral competitions and theme shows have no difference with professional performances based on the platform of professional colleges. Although professional advantages make it less difficult to develop, they have lost the genre of novelty, diversity, and education in fun, which are essential elements attracting students, so that students lack the subjective sense of participation, subjective initiative to think and solve problems. So, it is difficult to achieve the expected results.

\section{INNOVATIVE IMPLEMENTATION CASES OF MUSIC MAJORS' INTEGRATION OF SOCIAL PRACTICE AND PROFESSIONAL EDUCATION IN UNIVERSITIES}

In summary, based on the professional education practice curriculum, professional practice activities, and the actual status quo of social practice of music majors, it can be concluded that music students should bid farewell to the traditional art practice centered on daily teaching classrooms when they conduct campus practice activities in universities. But they still need to uphold a certain teaching purpose in practical activities as an important part of professional art education. In the creation of a different learning environment and environment for students from the classroom teaching mode, the double education effects of professional education and quality education should be flexibly used to achieve the purpose of broadening the artistic vision, stimulating the ability to innovate, exercising the ability to apply, and improving the professional skills to 3 enhance the comprehensive ability of music majors.

In combination with the above core ideas, the author has designed and launched a series of activities aimed at the integration of social practice and professional education for college students majoring in music. Here are two innovative examples of different education directions to be briefly described.

\section{A. Integrating Specialized Education into Social Practice and Strengthening Students' Ideals and Beliefs - Collecting Folk Songs Activity of Art Works Creation Series Themed with "Walker and Imagination"}

a) Activity theme: Based on specialized characteristics, taking music collecting folk songs as a platform, we broaden students' specialized horizon, provide inspiration materials for students' music creation and interpretation, combine the improvement of specialized skills and ideological education in an all-round way, so as to promote students' growth and success and achieve the educating goal of "excellent skills and moral integrity".

b) Activity mode: In light of different theme settings and collecting places, such as the collecting folk songs activity of "walker and imagination--the echo of history", series of activity lesson can be carried out with distinct theme, for example, the collecting and creation activity themed with patriotic history belief conducted by Changchun Imperial Palace of Manchukuo and Memorial of the Colonized Northeast China.

On the basis of students' enrollment situation, adopt the way of "hunger marketing" and select 20 to 30 students to participate in this activity. The means of "hunger marketing" not only can improve students' enthusiasm, but also can enhance their concern on this activity. Due to the precious opportunity, different themes can inspire students' creative enthusiasm, and ensure the effectiveness of activities at the same time.

The enrollment can be divided into three groups: dance and music creation group, original work creation group and musical composition creation group. After the completion of each activity, a work exhibition will be formed, which should be pushed to the whole grade by the public platforms. Outstanding works will be selected and presented for each semester.

\footnotetext{
Shan Hongzhe. On the Methods and Measures of Art Practice of

Music Education [J]. Art Education, 2015
}

\footnotetext{
Feng Ai, Fangbing. Guide to Social Practice of College Students [G]. Beijing: Social Sciences Academic Press, 2005.8
} 
c) Activity effect: Music is a discipline that combines professional skills and perceptual thinking. Under the educational model of colleges and universities, there are a large number of college students. In order to achieve teaching goals, students are inevitably bound by the framework of curriculum and assignment. They like the products by volume production in the factory and loss the artistic essence of music. Rely on the form of "collecting folk songs", the art works creation series activities excavate the different perspectives of each students. The same way as the fine arts of arts specialties can make all the students facsimile the same plane workings. Although this activity has trained students' professional skills, it limits the students' artistic ideas and creative ideas. However, in the collecting folk song activity, even if they are under the same scenery, there will never be the same student's work. The same is true for music practice activities.

Some of the students participating in the activity said that the collecting folk songs activity of theme art works creation series expanded a fresh and wide space for divergent thinking, and the difference from the passive acceptance of educational courses was to actively mobilize their creative consciousness. Other students said that they felt and thought in the real environment, experienced the emotions of revolutionary songs under the scene of historical reappearance, gained more artistic practice knowledge using forms, and more were willing to accept it subjectively, which greatly improved their interest in learning, eased the aesthetic fatigue and learning inertia in school education, and broadened their own vision, enhanced their own thinking creativity and understanding ability, and improved their own capabilities.

\section{B. Improving Students' Professional Quality and Serving the Construction of Campus Culture - Slowly Talk about Music and Dance Salon in "Beautiful Music Time"}

a) Activity theme: We should encourage students to serve the campus and society on a professional basis, extend and popularize specialized subject content, and develop students' comprehensive skills in transforming and applying personal specialized knowledge; meanwhile, we provide a platform for other professional students to exchange interest, enhance their literacy, and cultivate sentiment in their busy student life.

b) Activity mode: Taking music majors as the salon organizer, we will make an art infiltration, simple analysis and science popularization form the perspective of professional popularization, and the live vocal music performance and instrumental music performance will be interspersed in the informal discussion.

The students can independently declare the theme of the salon, and the topics will be centered on music and dance, and they will independently design the links and contents of salon. After the topic is selected, they will rehearse and prepare it, and confirm the theme, and then produce the propaganda poster. The poster will be publicized throughout the school. The salon is for students who are from other colleges and interested in the theme.
In the salon activity, the author guides students to pay attention to the effectiveness and diversity of activities. For example, in the activity of vocal music technique popularization theme salon that "sing songs and songs make you happy", the vocal music majors will act as a teacher to explain method of sound production and respiratory control to the non-vocal music majors, and make a song audition. This theme is very practical, and the number of students in the registration link will be controlled at 15 to ensure that music majors can fully mobilize their abilities in the teaching process, and to enhance the personal experience of non-vocal music majors. In the activity of folk music instrument popularization theme salon of "ancient sound and country rhyme", the folk music majors mainly explain the structure of the musical instrument, the way of sounding, historical development and live performance. Participants mainly learn by listening, and the number of participants can be set at 30-40.

c) Activity effect: The most central change during slowly talking about music and dance salon in "beautiful music time" is the change of the role, from student to "teacher" and "lecturer". Students participating in the activities said that as a teacher, they gained recognition of their own artistic level and professional ability through elaborate rehearsal and preparation in the practical activity. They learned how to produce posters, and organized participants, which gave them a sense of fulfillment and satisfaction subjectively, and trained their interpersonal skills.

In addition, the practical activity according with and give full play to their professional advantages has improved the initiative of professional learning. The students analyzed the major from the perspective of the speaker, and gained a new understanding. The knowledge that has learned can be continuously consolidated and developed through the transformation of knowledge into practical work ability, and at the same time, they have found their own problems intuitively. In terms of the comprehensive application of professional knowledge and language expression, there is still room for improvement. Students' awareness of social responsibility should be strengthened while guiding them to promote music and art culture in schools. Students should help build the campus culture and give back to society with their own directors while educating themselves and others.

\section{THE IMPORTANCE OF DEVELOPING INTEGRATION ACTIVITIES OF SOCIAL PRACTICE AND PROFESSIONAL EDUCATION}

The development of social practice activities must not be separated from the core theme that promotes and cultivate the essence of the students, and be a powerful supplement to the practical teaching outside the curriculum system. We must connect theory with practice and understand theory in practice. It is crucial to emphasize the cultivation of students' decisionmaking power, innovation ability and interpersonal skills, while developing the basic skills of music theory and practical application skills. Only by strengthening the effective training of skills and moral integrity and fully educating people, can we provide a strong guarantee for the students to "stand on the platform firmly and sing loud", so as to adapt to the needs of 
the talents in the new situation. ${ }^{4}$ (A New Exploration on the "Five in One" Music Practice Teaching Mode).

\section{CONCLUSION}

To sum up, combined with the actual development effects of innovative activities, it can be seen that music majors conduct integration activities of social practice and professional education in university, which is an essential link that should be paid attention to in university. This enhances students' professional skills and improves their comprehensive abilities. Diversified themes and forms of activities can also serve as lubricating oils and combustion assistants in students' learning and life, playing an important role in ideological adjustment and learning motivation. Students have gained a deeper understanding of their career choices and development through field training in practical activities, while enhancing the professional knowledge of music majors.

\section{REFERENCES}

[1] Wang Bingnan. Research on the Social Practice Mode of College Students Combined with Specialized Education [G]. Journal of North University of China (Social Science Edition), 2011. 王秉楠. 结合专业. 教育的大学生社会实践模式研究 $[\mathrm{G}]$. 中北大学学报（社会科学版）, 2011

[2] Feng Ai, Fangbing. Guide to Social Practice of College Students [G]. Beijing: Social Sciences Academic Press, 2005.8. 冯艾, 范冰主编. 大 学生社会实践导读 [G]. 北京: 社会科学文献出版社, 2005.8

[3] Shan Hongzhe. On the Methods and Measures of Art Practice of Music Education [J]. Art Education, 2015. 单宏哲. 谈音乐教育艺术实践的方 法与措施[J]. 艺术教育, 2015

[4] Yin Hongxia. A New Exploration on the "Five in One" Music Practice Teaching Mode [G]. Art and Literature for the Masses, 2013.8. 段红霞. “五位一体”音乐实践教学模式新探索 [G]. 大众文艺, 2013.8

Yin Hongxia. A New Exploration on the "Five in One" Music Practice Teaching Mode [G]. Art and Literature for the Masses, 2013.8 